\title{
Comportamentos e atitudes essenciais na interpretação de acompanhamento: A perspectiva dos clientes
}

\section{Essential behaviors and attitudes in escort interpreting): a clients' perspective}

\author{
Milton L. Torres* \\ J osiane da Silva*
}

Resumo: Esta pesquisa se volta para a modalidade da interpretação de acompanhamento (escort interpreting) com o objetivo de analisar as questões referentes ao trabalho do intérprete, a partir do ponto de vista de seus clientes. Discute-se aqui a atuação desse tipo de intérprete no mercado da cerâmica, a fim de identificar quais seriam os elementos essenciais, na prática interpretativa, que deveriam nortear o trabalho do profissional da interpretação de acompanhamento quando atuando na área de negócios. Os resultados apontam para o fato de que os intérpretes não só devem ter conhecimentos técnicos na área, mas também familiaridade com os equipamentos. Dentre outros aspectos, a pesquisa mostrou ainda que 0 intérprete precisa ter conhecimento amplo das culturas com as quais trabalha, ser pontual e cortês, agir como profissional e se vestir adequadamente.

Palavras-chave: Tradução e interpretação; Escort interpreting; Modalidades de Interpretação.

\footnotetext{
* Coordenador do curso de Tradutor e Intérprete no Centro Universitário Adventista de São Paulo, em Engenheiro Coelho, SP. E-mail: milton.torres@unasp.edu.br.

* Bacharela no curso de Tradutor e Intérprete pelo Centro Universitário Adventista de São Paulo, em Engenheiro Coelho, SP. E-mail: josy_estiva@hotmail.com.
} 
TORRES, M. L.; SILVA, J . - Comportamentos e atitudes essenciais na interpretação de acompanhamento:

A perspectiva dos clientes

Abstract: This paper studies escort interpreting in order to examine issues pertaining to the work of the interpreter from the point of view of their customers. This study discusses the performance of this type of interpreter in the ceramic market so as to point to the essential elements that will make an escort interpreter successful when working in the business environment. The results point to the fact that interpreters must not only have expertise in the field, but also familiarity with the equipment pertaining to that industry. Among other aspects, this survey also shows that the interpreter must have cultural knowledge as well as other characteristics such as punctuality, friendliness, professional posture and proper attire.

Key words: Translation studies; Escort interpreting; Interpreting modes.

\section{Introdução}

0 ato de interpretar exprime, através da linguagem, diferenças culturais entre povos que, muitas vezes, são tidas como impossíveis de correlacionar. Por isso, faz-se necessário que o intérprete tenha habilidades além daquelas ensinadas pelos estudos tradutológicos. Para alcançar 0 objetivo maior da comunicação e entendimento entre as partes, o intérprete necessita compreender que "a interpretação não é um processo mecânico, mas criativo, dependendo principalmente de uma visão de mundo" (TORRES 2012:18). Segundo HeRBERT (1952), uma das missões do intérprete é a de promover a aquisição de um conhecimento mais abrangente e profundo entre indivíduos de diferentes comunidades para que estes consigam alcançar um comum acordo. Pode-se dizer que a interpretação é, portanto, uma atividade indispensável sempre que houver interação entre culturas diferentes.

Para se tornar um profissional competente, o intérprete deve se preparar previamente, e uma das qualidades mais exigidas nessa profissão é a postura ética. Espera-se que o intérprete atue honestamente, preservando as reais intenções do orador. É através da ética que o intérprete conseguirá analisar os caminhos e meandros que devem ser percorridos durante seu 
TORRES, M. L.; SILVA, J . - Comportamentos e atitudes essenciais na interpretação de acompanhamento:

A perspectiva dos clientes

trabalho. Ou seja, a ética terá, então, a função de nortear a direção que a interpretação tomará. À medida que o intérprete analisa o que lhe é apresentado, ele terá sempre o seu "ponto de referência" para analisar a forma como the é cabível traduzir. Sua postura indica as características e valores que cultiva. Portanto, o trabalho do intérprete vai além de tarefas que the são mecanicamente designadas em sua profissão.

A título de exemplo, pode-se mencionar o que aconteceu diversas vezes ao intérprete da Casa Branca, Harry Obst, que interpretou para sete presidentes americanos. Por vezes, o presidente americano Lyndon B. J ohnson pedia conselhos a Obst, já que o presidente sabia que ele havia trabalhado em administrações anteriores e conhecia os líderes estrangeiros e seus estilos de negociação. 0 também presidente americano Jimmy Carter pediu para que Obst criasse uma frase impactante em alemão para o seu discurso de 1978 no Airlift Memorial, em Berlim. Obst criou a seguinte frase: "Wasimmer sei, Berlin bleibt frei", que significa: "Não importa o que aconteça, Berlim permanecerá livre". No dia seguinte, a frase de Obst estava na capa dos maiores jornais de Berlim e na maioria dos jornais da Alemanha (Kelly, ZETZSCHE 2012:55-56).

Assim, ao contratar o intérprete, o cliente se depara com questões delicadas referentes ao trabalho do profissional, que envolvem principalmente a questão da ética e cultura, incluindo aspectos como o modo como 0 intérprete se veste, a maneira como ele deve se portar, seu tom de voz, etc. Esses são aspectos que podem, muitas vezes, desagradar ao cliente. Assim, pergunta-se quais seriam os elementos essenciais que devem permear 0 trabalho do intérprete de acompanhamento quando atuando na área de negócios. Para responder a esse questionamento, surge a hipótese de que os aspectos técnicos, éticos e de conduta devem ser rigorosamente compatíveis com as exigências do cliente, constituindo elementos essenciais que devem permear a atuação do intérprete de acompanhamento quando atuando na área de negócios. Visto que o foco deste estudo é a modalidade da 
TORRES, M. L.; SILVA, J . - Comportamentos e atitudes essenciais na interpretação de acompanhamento:

A perspectiva dos clientes

interpretação de acompanhamento (escort interpreting) sob a perspectiva do cliente, o objetivo geral foi fazer uma análise de algumas das questões pertinentes ao trabalho do intérprete diretamente com o cliente e, a partir dos relatos e exemplos da literatura pertinente e de entrevistas com clientes, analisar os aspectos recomendáveis e não recomendáveis na conduta do intérprete de acompanhamento na área de negócios no que diz respeito às questões técnicas, éticas, comportamentais e culturais. A parte qualitativa da pesquisa voltou-se para clientes que já haviam contratado um intérprete profissional. Nosso principal objetivo foi, portanto, verificar os pontos considerados negativos e positivos no trabalho do profissional.

Nesse contexto, aplicamos um questionário semiestruturado, seguindo a abordagem qualitativa, direcionado a clientes que já haviam utilizado 0 serviço de um intérprete profissional. Com relação ao critério de escolha de pessoas, foi feita uma amostra de conveniência. Isto é, participaram da amostra pessoas do sexo masculino e feminino provenientes dos seguintes países: Alemanha, Brasil, China, Itália e Estados Unidos, tendo como língua materna o alemão, o português, o mandarim, o italiano ou o inglês. Após a aplicação do questionário, utilizou-se a análise de conteúdo (MORAES 1999) para a avaliação e sistematização dos resultados. Por se tratar de uma pesquisa envolvendo seres humanos, os entrevistados assinaram um Termo de Consentimento Livre e Esclarecido, conforme previsto na Resolução CNS 196/ 96 do Conselho Nacional de Ética em Pesquisa.

Dividiu-se a pesquisa em três partes. Na primeira, apresentam-se breves considerações históricas e teóricas sobre a interpretação a fim de discutir os aspectos recomendáveis e não recomendáveis na conduta do intérprete de acompanhamento na área de negócios no que diz respeito às questões técnicas, comportamentais e culturais. Na segunda parte, analisa-se a interpretação de acompanhamento no contexto dos desafios relacionados a traduções e interpretações equivocadas que causaram problemas nas mais diversas áreas, como política, médica, financeira, etc. Na última e mais 
TORRES, M. L.; SILVA, J . - Comportamentos e atitudes essenciais na interpretação de acompanhamento:

A perspectiva dos clientes

importante parte do trabalho, apresentam-se as entrevistas realizadas com os clientes e uma análise de seus resultados.

\section{A interpretação de acompanhamento no contexto das modalidades de Interpretação}

Segundo Kelly e ZetZSCHe (2012:xiii), a tradução influencia as diversas áreas de nossa vida: um livro que lemos, um filme a que assistimos, a comida que comemos, a religião que praticamos, etc. A tradução possibilita que guerras sejam impedidas, que a economia global seja movimentada, e até previne surtos de doenças. Exemplos que Kelly e ZetZsche (2012) citam desses benefícios incluem economia de dinheiro em situações em que, devido ao trabalho do intérprete, diagnósticos médicos são feitos com maior rapidez, evitando gastos com exames adicionais para descobrir a doença do paciente (p. 8). No Haiti (p. 12-13), após o terremoto, intérpretes usaram SMS para traduzir a língua crioula e ajudar a salvar vidas.

0 trabalho do intérprete é o de facilitar e fazer acontecer a comunicação oral entre duas ou mais pessoas que fazem uso de línguas diferentes. Ele é, portanto, o elo de ligação entre diferentes culturas. A interpretação é uma profissão muito antiga e com um papel de importante relevância para a história da humanidade, pois permite o diálogo entre diferentes comunidades. A interpretação é geralmente dividida em modalidades tradicionais: intermitente, consecutiva, cochichada (chuchotage) e simultânea (SCHÄFFER 2012:28). Com o avanço da tecnologia e o surgimento de novas necessidades de comunicação, a partir do século XX diversificou-se a gama de situações interpretativas em que essas modalidades podem ser usadas: interpretação de conferência, comunitária, por retransmissão, de 
TORRES, M. L.; SILVA, J . - Comportamentos e atitudes essenciais na interpretação de acompanhamento:

A perspectiva dos clientes

ligação, de acompanhamento, médica, presencial e por telefone, entre outras (GAZETA 2012:163-175).

$\mathrm{Na}$ interpretação de acompanhamento, o intérprete faz constante troca de idiomas (Gentile, Ozolins, VAsilaKaKos:1996), como, por exemplo, do português para o inglês e vice-versa, ligando-se dessa maneira a ambos os interlocutores. A interpretação de acompanhamento é geralmente realizada por meio da interpretação intermitente, a qual ocorre quando o intérprete espera 0 interlocutor terminar a ideia e, logo em seguida, a interpreta no outro idioma. Exemplo disso é o que ocorre em uma reunião formal e bilíngue - o intérprete espera um dos locutores concluir a ideia e, depois disto, transfere para o idioma do outro locutor o que foi dito (GAZETA 2012:168).

Como liaison interpreting, a interpretação de acompanhamento é geralmente destinada a pessoas que estão realizando visitas in loco, como funcionários do governo, executivos, investidores, observadores e afins (BLAAUW, RANKIN 200?). ${ }^{1} 0$ intérprete acompanha o cliente ou até mesmo uma pequena delegação a diversos tipos de eventos, como, por exemplo, a uma feira ou jantar de negócios, entrevistas ou reuniões (GAZETA 2012:168). Segundo Gonzales et al. (1991 apud BLAaUw, RANKIn 200?:28), a interpretação de acompanhamento (escort interpreting):

é um tipo de interpretação marcado pela espontaneidade e pelo amplo espectro de situações em que os intérpretes podem encontrar-se, desde reuniões formais, passeios em fábricas, até coquetéis. 0 modo mais utilizado neste tipo de interpretação é o consecutivo e é geralmente limitado a algumas frases de uma só vez.

1 Segundo HSIEH (2003:284), liaison interpreting é um termo inclusivo que engloba vários tipos de interpretação. De maneira mais abrangente, compreende atividades de interpretação nas quais há uma interação do intérprete com pelo menos duas partes distintas, mesmo por meio do telefone, caso em que não há contato pessoal. Liaison interpreting é, portanto, um tipo de interpretação realizado em duas línguas diferentes pela mesma pessoa (GENTILE et al., 1996 apud HSIEH 2003:285, LA SALA 2008). 
TORRES, M. L.; SILVA, J . - Comportamentos e atitudes essenciais na interpretação de acompanhamento:

A perspectiva dos clientes

Já OBST (2010:171) define o intérprete de acompanhamento como aquele que acompanha os visitantes estrangeiros durante sua visita ao país de origem do intérprete. Essas pessoas vêm visitar o país geralmente quando convidadas por programas oficiais ou até mesmo por programas corporativos, esportivos, governamentais, educativos e de pesquisa. Segundo ele, o intérprete de acompanhamento, em algumas ocasiões, pode também acompanhar pessoas de seu próprio país em uma visita a um país estrangeiro (OBST 2010:171).

Há uma estreita e contínua interação entre 0 intérprete de acompanhamento e o cliente, o que possibilita uma comunicação que leva em consideração as particularidades da cultura, inclusive a escolha da forma mais apropriada de portar-se durante cada situação. Portanto, o intérprete deve conhecer bem a cultura local e a do visitante. Como a cultura está intrinsecamente ligada ao idioma, o intérprete expõe-se a muitos desafios. Em diversos casos, senão em todos, o intérprete se depara com questões que exigem um conhecimento bem detalhado de determinada cultura. KeLLY E ZetZSCHE (2012:20) citam o caso da palavra câncer que não existe entre o povo hmong, o que levou médicos e linguistas da Universidade da Califórnia a se esforçarem para criar um neologismo em hmong para a palavra em questão. $E$, ainda assim, os intérpretes têm que explicar para os hmong recémchegados às comunidades norte-americanas alguns termos médicos que são relativamente simples. Os intérpretes que realizam este tipo de trabalho são mais do que simplesmente uma "ponte" entre idiomas diferentes (KellY, ZetZSCHE 2012:20). Apesar disso, em alguns casos, os intérpretes são vistos como traidores. Isso ocorre quando eles "navegam entre dois mundos" e, por essa razão, "são geralmente vistos com suspeita por um dos lados ou, pior ainda, pelos dois lados" (Kelly, Zetzsche 2012:39). Kelly e ZetZsChe (2012:40) consideram que, visto que muitos intérpretes foram mortos no Iraque e no Afeganistão (sendo que, em muitos casos, a família deles também), por trabalharem para o governo americano, a frase traduttore, traditore 
TORRES, M. L.; SILVA, J . - Comportamentos e atitudes essenciais na interpretação de acompanhamento:

A perspectiva dos clientes

("tradutor, traidor") está sendo modificada pelos intérpretes sobreviventes, que ainda temem ser assassinados, para traduttore, tradito ("tradutor, traído") (Kelly, ZetZsChe 2012:41).

Em situações difíceis geradas por um mal-entendido, o intérprete precisa de "tato e diplomacia" (BLAaUw, Rankin 200?:34). Ele tem que saber como se comportar em relação às pessoas com as quais a interpretação 0 coloca em contato, não importando o preconceito que essas pessoas possam expressar em relação a sua atuação. Em casos delicados, o intérprete precisa ser o primeiro a fazer uso do bom senso. É dever do intérprete saber lidar com diferentes culturas, antecipando e evitando possíveis interpretações equivocadas, mal-entendidos e até mesmo algum tipo de insulto ou ofensa (BLAAUW, RANKIN 200?:32).

\section{A interpretação de acompanhamento no contexto dos desafios tradutórios e de face validity}

Kelly e ZetZSCHE (2012) apresentam vários exemplos de interpretações equivocadas que causaram problemas na política, medicina e área financeira. Um desses exemplos diz respeito a uma indenização por imperícia médica no valor de 71 milhões de dólares por conta de o paciente ter ficado tetraplégico na ocasião. A família e os amigos do paciente Willie Ramirez, que só falavam espanhol, tentaram descrever sua condição para os paramédicos e médicos. Foi, então, que um dos membros da equipe, que era bilíngue, resolveu ajudar realizando, assim, a interpretação. A família de Ramirez achava que ele estivesse com uma intoxicação alimentar (food poisoning). Portanto, disseram 
TORRES, M. L.; SILVA, J . - Comportamentos e atitudes essenciais na interpretação de acompanhamento:

A perspectiva dos clientes

ao intérprete que Ramirez estava intoxicado. 0 intérprete traduziu "intoxicado" como intoxicated. Porém, em inglês, intoxicated diz respeito a alguém que fez uso demasiado de drogas ou álcool e, assim, Ramirez que, na verdade, estava com uma hemorragia intracerebral, esperou durante muito tempo para ser atendido e acabou ficando tetraplégico (Kelly, ZetZsChe 2012:3).

A interpretação de acompanhamento tem desafios tradutórios semelhantes aos dos demais tipos de interpretação e das demais modalidades de tradução. Afinal de contas, de acordo com Dryden (apud MiLton, ViLla, 2012:7-8), o intérprete tem que lidar com um grande número de exigências que enfrenta:

É como dançar sobre uma corda com as pernas amarradas: pode-se evitar uma queda sendo-se cauteloso, mas não se pode esperar que os movimentos sejam elegantes; e na melhor das hipóteses não passa de uma tarefa estúpida, pois nenhuma pessoa sensata se exporia ao perigo em troca de aplausos por ter escapado sem quebrar o pescoço.

Uma interpretação inadequada pode ocasionar danos, principalmente quando não é feita por um profissional qualificado. Não se pode esquecer, contudo, da postura do intérprete com relação ao comportamento ético e cultural, visto que a ética e o conhecimento de mundo são considerações de grande importância e que devem sempre ser levadas em conta no processo tradutório.

Isso nos leva a outra consideração. Trata-se da questão da face validity no trabalho do intérprete, definida como um tipo de avaliação em que determinada atividade, especialmente testes, é considerada válida por seus participantes e observadores não treinados (ANASTASI 1988). Face validity é, portanto, uma espécie de exame superficial de uma atividade por aqueles que não são peritos nela (SARTORI 2009: 750). INGRAM (1977:18) a define brevemente 
TORRES, M. L.; SILVA, J . - Comportamentos e atitudes essenciais na interpretação de acompanhamento:

A perspectiva dos clientes

como "credibilidade à primeira vista ou reconhecimento público". A partir das respostas dadas pelos entrevistados, percebeu-se, como será mostrado a seguir, que esta é uma importante questão referente ao desempenho profissional do intérprete.

\section{Entrevistas com intérpretes que atuam no ramo da cerâmica}

Nesta seção, apresenta-se a pesquisa de campo, de natureza qualitativa, sobre a conduta profissional do intérprete de acompanhamento. Primeiramente, apresentam-se os dados relacionados ao tempo, idiomas e locais onde foram utilizados os serviços de intérpretes. Depois disso, aplica-se o método da análise de conteúdo. Este tipo de análise é constituído por uma metodologia de pesquisa com fins de descrever e interpretar os conteúdos de materiais textuais, em uma busca teórica e prática, principalmente na área de investigação social. Assim, a análise de conteúdo foi escolhida devido à necessidade de dar enfoque principalmente aos discursos dos clientes entrevistados (MORAES 1999).

o questionário semiestruturado enviado a clientes de intérpretes de acompanhamento continha 18 perguntas. A parte do questionário que contemplou as informações gerais dos respondentes se limitou às dez primeiras perguntas: nome, idade, sexo, nacionalidade, ocupação, grau de instrução, tempo de recurso aos intérpretes, países visitados, línguas usadas e duração das viagens. Já a parte que diz respeito às perguntas qualitativas e que serviram para a análise de conteúdo foi composta de oito questões relacionadas à profissão e atuação do intérprete de acompanhamento. 
TORRES, M. L.; SILVA, J . - Comportamentos e atitudes essenciais na interpretação de acompanhamento:

A perspectiva dos clientes

A pesquisa foi enviada por e-mail, entre os dias três e 13 de setembro de 2013, para 22 clientes. 0 email continha um link que os direcionava até uma página específica da internet onde a pesquisa foi criada (www.typerform.com). Havia um link específico para as pesquisas em português que foi enviado para os clientes brasileiros (https:// josy.typeform.com/to/ISdRRg) e um link específico para as pesquisas em inglês, que foram enviadas para os clientes dos demais países (https:// josy. typeform.com/ to/lg4DYT).

Antes de começar a responder ao questionário propriamente dito, os entrevistados foram direcionados a uma página que continha o Termo de Consentimento Livre e Esclarecido, previsto na Resolução CNS 196/96 do Conselho Nacional de Ética em Pesquisa. Se não concordassem, não Ihes seria possível responder às questões. De qualquer forma, de acordo com o Termo, os dados pessoais dos clientes foram mantidos em sigilo.

Recebemos um total de 13 questionários respondidos. Porém, como 0 objetivo era fazer uma pesquisa qualitativa, resolvemos descartar quatro desses questionários que não foram completamente respondidos. A justificativa dada por esses clientes foi de que eles não eram responsáveis por contratar os intérpretes envolvidos na viagem. Nesses casos, fizeram uso de agentes comerciais que falavam ambas as línguas necessárias. A maioria dos clientes escolhidos atua predominantemente na área de cerâmica e é originária de diversos lugares do mundo: Alemanha, Brasil, China, Estados Unidos e Itália.

Com relação ao sexo, nota-se uma predominância masculina atuando na área de cerâmica, pois apenas um respondente pertencia ao sexo feminino. A idade dos pesquisados varia de 29 a 71 anos, tendo uma média geral de 47 anos, o que nos permite dizer que, neste caso, a utilização de intérpretes não está restrita a nenhuma faixa etária específica. Já com relação à ocupação dos participantes, a pesquisa mostra que quatro atuam na área comercial, dois são presidentes de empresa, dois atuam na área de engenharia e um na 
TORRES, M. L.; SILVA, J . - Comportamentos e atitudes essenciais na interpretação de acompanhamento:

A perspectiva dos clientes

área de negócios. No que diz respeito ao grau de instrução dos participantes, seis concluíram o Ensino Superior e três fizeram mestrado.

Em seguida, apresentam-se as perguntas com uma breve explicação ou análise de conteúdo das respostas. A numeração é a mesma do questionário.

\section{Há quantos anos faz uso de intérpretes ao visitar um país estrangeiro?}

O uso de intérprete varia de três a 25 anos, sendo a média geral de seis anos. Alguns participantes não souberam precisar há quanto tempo faziam uso de intérpretes e responderam que usavam intérpretes "há anos" ou "frequentemente".

\section{Que países o $\operatorname{Sr}(a)$. visitou acompanhado de um intérprete?}

As maiores incidências são de americanos que visitaram o Brasil e de americanos e brasileiros que foram para a China (quatro visitas para cada país). Logo em seguida, os países mais visitados foram Alemanha, Índia, Itália, Polônia e Rússia (com dois visitantes para cada país) e, com uma visita para cada país, temos Áustria, Espanha, Indonésia, Irã, Japão, Malásia, México, Tailândia, Turquia e Ucrânia.

\section{Que línguas foram usadas nas viagens?}

De acordo com o país visitado, predomina o uso da língua local pelo intérprete na hora da interpretação para o cliente. Na maioria das vezes, a língua utilizada era o inglês. Exemplos de línguas utilizadas: português, inglês, alemão, russo, espanhol, malaio, tailandês, mandarim, italiano, polonês e hindi.

\section{Qual a duração das viagens?}

A duração das viagens varia de cinco a 21 dias, sendo que a média geral é de 4,4 dias. 
TORRES, M. L.; SILVA, J . - Comportamentos e atitudes essenciais na interpretação de acompanhamento:

A perspectiva dos clientes

\section{Ao contratar um intérprete, você tem preferência por sexo (feminino ou masculino)?}

Nenhum participante disse ter preferência por sexo ao contratar um intérprete. Um dos participantes, porém, fez o seguinte comentário adicional: "Nesse ambiente industrial cerâmico/refratário, é mais comum encontrar pessoas do sexo masculino. Porém, já utilizei os serviços de intérprete do sexo feminino na Índia e China".

\section{Você tem preferência por intérpretes autônomos ou de agências?}

Seis dos participantes disseram não ter preferência por um tipo específico de intérpretes. Porém, um deles fez o seguinte comentário: "não tenho preferência, desde que o intérprete seja capaz de facilitar minha viagem". Um dos participantes disse que prefere intérpretes autônomos e, quando questionado sobre a razão disso, a resposta foi que o custo é menor. Outro respondente disse que prefere intérpretes de agência pela comodidade, pois a agência providencia o intérprete e ajuda na organização da viagem. Outro também respondeu que já usou os dois tipos de serviços com boas e más experiências, e um disse que já usou o serviço apenas uma vez, optando por um intérprete autônomo. Nota-se, portanto, que, de maneira geral, não há preferência pelo tipo de intérprete a ser contratado.

\section{Entre os intérpretes contratados, qual Ihe foi mais útil? Por quê?}

Apenas um dos entrevistados disse que não teve nenhuma experiência para relatar e outro citou apenas o Brasil como resposta. Abaixo, seguem os relatos dos demais participantes: 
TORRES, M. L.; SILVA, J . - Comportamentos e atitudes essenciais na interpretação de acompanhamento:

A perspectiva dos clientes

\begin{tabular}{|c|c|}
\hline País de origem & Relato \\
\hline Alemanha & $\begin{array}{l}\text { "Que tem conhecimento sobre as questões técnicas que } \\
\text { estão sendo discutidas". }\end{array}$ \\
\hline Brasil & "Chinês, maior afinidade com os clientes". \\
\hline Brasil & $\begin{array}{l}\text { "Foi quando estive na İndia e precisei de um intérprete } \\
\text { para tradução simultânea de uma palestra que ministrei. } \\
\text { Utilizei a língua inglesa e a intérprete fazia a versão para } \\
\text { a língua local. Teria sido impossível ministrar o seminário } \\
\text { sem a presença dessa intérprete". }\end{array}$ \\
\hline China & $\begin{array}{l}\text { "Aqueles que não sejam bons apenas na linguagem, mas } \\
\text { também que sejam familiarizados com o negócio ou que } \\
\text { forneçam conselhos úteis para a minha estada". }\end{array}$ \\
\hline Estados Unidos & $\begin{array}{l}\text { "Aqueles que são mais técnicos, já que nosso trabalho é } \\
\text { industrial". }\end{array}$ \\
\hline Estados Unidos & $\begin{array}{l}\text { "Na China, o intérprete utilizado tinha mais familiaridade } \\
\text { com os equipamentos e questões técnicas. Muito útil". }\end{array}$ \\
\hline Estados Unidos & "Brasil. Deu-nos mais informacões sobre a cultura". \\
\hline
\end{tabular}

Tabela 1 - Intérprete mais útil

As respostas sugerem que o conhecimento técnico na área de cerâmica é muito importante para a maioria dos participantes. Alguns citaram também a importância da familiaridade com os equipamentos em questão. A afinidade com o cliente foi citada, bem como a questão cultural do país visitado, situação em que entra o conhecimento de mundo que o intérprete deve ter.

\section{Entre os intérpretes contratados, qual Ihe foi menos útil? Por quê?}

Um dos entrevistados disse que não teve nenhuma experiência para relatar nesta questão, e três dos participantes não responderam a essa questão. Abaixo, seguem os relatos dos demais participantes: 
TORRES, M. L. ; SILVA, J . - Comportamentos e atitudes essenciais na interpretação de acompanhamento:

A perspectiva dos clientes

\begin{tabular}{|c|l|}
\hline País de origem & \multicolumn{1}{|c|}{ Relato } \\
\hline Alemanha & $\begin{array}{l}\text { "Com muito pouco conhecimento sobre a indústria e } \\
\text { produtos utilizados". }\end{array}$ \\
\hline Brasil & $\begin{array}{l}\text { "Na Polônia. Em razão do nível das pessoas envolvidas, a } \\
\text { língua Inglesa foi suficiente para a comunicação". }\end{array}$ \\
\hline China & "Aqueles que não sabem nada além da língua". \\
\hline Estados Unidos & $\begin{array}{l}\text { "Na China, os dialetos são tão diferentes de região para } \\
\text { região, e um intérprete específico deve ser escolhido para } \\
\text { uma região específica". }\end{array}$ \\
\hline Estados Unidos & $\begin{array}{l}\text { "Indonésia: Após um minuto de fala, o intérprete disse } \\
\text { que a resposta foi 'sim'. Eu não recebi todas as } \\
\text { informações". }\end{array}$ \\
\hline
\end{tabular}

Tabela 2 - Intérprete menos útil

As respostas sugerem que o conhecimento técnico-cultural continua sendo muito importante. Em um dos comentários, fica claro que o cliente teve a sensação de que o intérprete não traduziu tudo o que foi falado. Isso nos remete à questão da face validity. Ou seja, mesmo que os clientes não compreendam a língua da interpretação, eles não se eximem de emitir seu parecer com base em sua perspectiva leiga. O lacônico "sim" do intérprete na Indonésia pode ter muito bem representado uma tradução precisa. Ainda sim, como não correspondeu ao tempo estimado pela expectativa do cliente, a interpretação acabou avaliada de forma negativa. Em uma profissão em que a face validity representa um importante componente no processo de recontratação ou não do intérprete, o profissional da interpretação necessita se mostrar sensível a esse elemento.

\section{Que comportamentos e/ou atitudes o levam a recontratar um determinado intérprete?}

Apenas um dos entrevistados não respondeu a esta questão. Abaixo, seguem os relatos dos demais participantes: 
TORRES, M. L.; SILVA, J. - Comportamentos e atitudes essenciais na interpretação de acompanhamento:

A perspectiva dos clientes

\begin{tabular}{|c|l|}
\hline País de origem & \multicolumn{1}{|c|}{ Relato } \\
\hline Alemanha & "Experiência, franqueza, cordialidade, boas maneiras". \\
\hline Brasil & "Atendimento e relacionamento com clientes". \\
\hline Brasil & $\begin{array}{l}\text { "Conhecimento técnico da área. Nesta minha função, } \\
\text { termos técnicos e conhecimento da área são de suma } \\
\text { importância. Por esta razão, faço uso da contratação de } \\
\text { pessoas que já tenham tido experiência com } \\
\text { equipamentos de produção industrial". }\end{array}$ \\
\hline China & "Aqueles que podem se tornar amigos". \\
\hline Estados Unidos & $\begin{array}{l}\text { "Pontual, que pesquisa previamente sobre o projeto e que } \\
\text { trabalha duro para aprender o projeto durante o } \\
\text { trabalho". }\end{array}$ \\
\hline Estados Unidos & $\begin{array}{l}\text { "Já que meu negócio é geralmente técnico, eu prefiro } \\
\text { alguém com esse tipo de conhecimento". }\end{array}$ \\
\hline Estados Unidos & "Que nos dá informações detalhadas sobre a cultura". \\
\hline "Confiança que eles estão trabalhando em meu \\
benefício".
\end{tabular}

Tabela 3 - Comportamentos e atitudes do intérprete para possível recontratação

O conhecimento técnico-cultural ainda é citado nesta questão. 0 intérprete deve ficar atento também se ele está passando a confiança necessária para o cliente. Pontualidade, experiência, cordialidade, entre outras, também são citadas aqui. De novo, temos a questão da face validity. O cliente dos Estados Unidos diz, por exemplo, que é importante que 0 intérprete the passe confiança. Outro cliente do mesmo país aprecia que 0 intérprete faça pesquisa prévia, algo que aquele não é capaz de avaliar de forma objetiva e que depende da impressão que este Ihe passa. Referências pontuais da parte do intérprete ao fato de ter feito pesquisa prévia podem ser suficientes para garantir, nesse caso, que se consiga a face validity. 
TORRES, M. L.; SILVA, J . - Comportamentos e atitudes essenciais na interpretação de acompanhamento:

A perspectiva dos clientes

\section{Que comportamentos e/ou atitudes o levam a não recontratar um determinado intérprete?}

Apenas um dos entrevistados não respondeu a esta questão. Abaixo, seguem os relatos dos demais participantes:

\begin{tabular}{|c|l|}
\hline País de origem & \multicolumn{1}{|c|}{ Relato } \\
\hline Alemanha & $\begin{array}{l}\text { "Discutir assuntos demoradamente com a contraparte } \\
\text { russa e depois não me envolver no tópico discutido ou } \\
\text { apenas mencioná-lo em três palavras". }\end{array}$ \\
\hline Brasil & "Quando não corresponde à expectativa". \\
\hline Brasil & $\begin{array}{l}\text { "Falta de conhecimento da área industrial, por exemplo, } \\
\text { uma pessoa que nunca entrou num ambiente fabril nem } \\
\text { está familiarizada com os processos industriais. Essa falta } \\
\text { de conhecimento técnico pode levar ao insucesso } \\
\text { comercial". }\end{array}$ \\
\hline China & $\begin{array}{l}\text { "Aqueles que sempre chegam atrasados ou parecem } \\
\text { cansados de ser intérprete". }\end{array}$ \\
\hline Estados Unidos & $\begin{array}{l}\text { "Não técnico e confuso em relação ao dialeto com o qual } \\
\text { estamos trabalhando". }\end{array}$ \\
\hline Estados Unidos & "Falta de conhecimento técnico/ de equipamento". \\
\hline Estados Unidos & "Se eles riem e fazem piada na língua nativa". \\
\hline
\end{tabular}

Tabela 4 - Comportamentos e atitudes do intérprete para possível não recontratação

A questão do conhecimento técnico continua sendo muito importante. Porém, tivemos outros tipos de comentários que mostram que o intérprete tem que ter cuidado com a postura, principalmente ao fazer piadas quando seu cliente não sabe o que está acontecendo. Envolver o cliente sempre que possível na conversa é também importante para que ele não se sinta excluído. Aqui foi citado novamente o fato de se resumir o que foi dito em poucas palavras. A pontualidade é novamente mencionada neste item, e uma informação nova é a da aparência de cansaço. Mesmo que esteja cansado do trabalho, passar essa impressão para o cliente nunca é uma boa escolha, pois pode diminuir a face validity do intérprete. 
TORRES, M. L.; SILVA, J . - Comportamentos e atitudes essenciais na interpretação de acompanhamento:

A perspectiva dos clientes

\section{Mencione um incidente em que o intérprete se mostrou essencial para o sucesso de sua viagem.}

Apenas um dos entrevistados não respondeu a esta questão. Abaixo, seguem os relatos dos demais participantes:

\begin{tabular}{|c|c|}
\hline País de origem & Relato \\
\hline Alemanha & "Em negociações bem sucedidas em preço". \\
\hline Brasil & $\begin{array}{l}\text { "A instalação de um equipamento de retífica de rolos } \\
\text { cerâmicos na China. Contactei a Universidade de Cantão e } \\
\text { pedi ajuda para encontrar uma pessoa que tivesse } \\
\text { conhecimento de máquinas similares a tornos mecânicos. } \\
\text { Tive a felicidade de contar com a assessoria de uma } \\
\text { intérprete profissional chinesa que havia morado em } \\
\text { Portugal. Durante o período que morou em Portugal, havia } \\
\text { trabalhado para um fabricante de tornos. Posso dizer que } \\
\text { foi um 'Iance' de sorte e muito me ajudou na instalação } \\
\text { correta do equipamento". }\end{array}$ \\
\hline China & $\begin{array}{l}\text { "O intérprete providenciou transporte local para mim } \\
\text { para que eu pudesse pegar todos os voos ou trens no } \\
\text { horário". }\end{array}$ \\
\hline Estados Unidos & "Múltiplas vezes na China e no Brasil". \\
\hline Estados Unidos & $\begin{array}{l}\text { "Ao descrever uma parte do que era para ser feito, o } \\
\text { intérprete se mostrou familiarizado com } 0 \text { processo de } \\
\text { fabricação". }\end{array}$ \\
\hline Estados Unidos & "Quando evitou que eu cometesse um erro social". \\
\hline Estados Unidos & $\begin{array}{l}\text { "Quando os detalhes podem determinar se uma } \\
\text { negociação adequada vai bem, a língua é a chave. Eles } \\
\text { devem parar e certificar-se que você receberá } 100 \% \text { da } \\
\text { informacão". }\end{array}$ \\
\hline Itália & $\begin{array}{l}\text { "Para ser um intérprete na área empresarial é essencial } \\
\text { ter conhecimento deste campo técnico em particular. } \\
\text { Caso contrário, será muito difícil transmitir o sentido } \\
\text { correto do discurso e transferir fluentemente informações } \\
\text { para os participantes da reunião". }\end{array}$ \\
\hline
\end{tabular}

Tabela 5 - Intérprete essencial para a viagem 
TORRES, M. L.; SILVA, J . - Comportamentos e atitudes essenciais na interpretação de acompanhamento:

A perspectiva dos clientes

A análise das respostas nos remete à questão de que o trabalho do intérprete vai além do ato de interpretar em si. Há casos citados em que o intérprete ajudou o cliente com o transporte. Há também o cliente que prefere contratar intérpretes que evitem que ele cometa "erros sociais". Isso aponta para a necessidade de que o intérprete tenha um amplo conhecimento de mundo, a fim de poupar constrangimentos a seus clientes. Finalmente, aparece, de novo, a exigência de familiaridade com os equipamentos e conhecimento técnico.

\section{Mencione um comportamento e/ou atitude que mais o incomodou por parte de um intérprete.}

Apenas um dos entrevistados não respondeu a esta questão. Abaixo, seguem os relatos dos demais participantes:

\begin{tabular}{|c|c|}
\hline País de origem & Relato \\
\hline Alemanha & $\begin{array}{l}\text { "Discutir assuntos demoradamente com a contraparte } \\
\text { russa, e depois não me envolver no tópico discutido ou } \\
\text { apenas mencioná-lo em três palavras". }\end{array}$ \\
\hline Brasil & “Não cumprimento de horário". \\
\hline Brasil & $\begin{array}{l}\text { "Muitas vezes o intérprete não entende logo 'de } \\
\text { primeira', e você tem que repetir o assunto várias vezes. } \\
\text { Outra atitude que incomoda é quando você percebe que o } \\
\text { intérprete abrevia o contexto. Ou seja, a pessoa fala uma } \\
\text { porção de palavras e o intérprete resume por conta } \\
\text { própria. Sempre fico desconfiado que possa estar } \\
\text { perdendo algo importante". }\end{array}$ \\
\hline China & $\begin{array}{l}\text { "Aqueles que não se preocupam com mais nada além de } \\
\text { seu pagamento ou que sempre confundem o que eu quero } \\
\text { dizer". }\end{array}$ \\
\hline Estados Unidos & $\begin{array}{l}\text { "Não vestido profissionalmente"; "Falta de } \\
\text { profissionalismo ao vestir-se". }\end{array}$ \\
\hline Estados Unidos & "Falta de interesse, autoabsorção". \\
\hline Estados Unidos & "Quando você sente que eles não estão trabalhando a seu \\
\hline
\end{tabular}


TORRES, M. L.; SILVA, J. - Comportamentos e atitudes essenciais na interpretação de acompanhamento:

A perspectiva dos clientes

\begin{tabular}{|l|l|}
\hline & favor e ficam incomodados com o cliente". \\
\hline Itália & $\begin{array}{l}\text { "Não ter palavras técnicas suficientes à disposição para } \\
\text { dar suporte à conversa". }\end{array}$ \\
\hline
\end{tabular}

Tabela 6 - Atitudes que incomodam por parte do intérprete

Estar vestido de forma adequada faz parte da postura ética do intérprete, assim como informar corretamente ao cliente o que a outra parte está dizendo para que ele não tenha a sensação de que está perdendo algo importante, conforme citado por um dos participantes. De fato, por sua recorrência como queixa, a abreviação do conteúdo parece ser um dos elementos mais deletérios para a face validity do intérprete.

Envolver o cliente na conversa e passar confiança para ele para mostrar que se está trabalhando a seu favor fazem parte do posicionamento ético do intérprete. A pontualidade e a questão técnica aparecem novamente nessas respostas, e podemos ver que os intérpretes não devem demonstrar que se sentem incomodados pela outra parte ou, ainda, que não têm interesse no que está acontecendo. Não devem, tampouco, demonstrar que estão demasiadamente preocupados com o pagamento. Além disso, dois dos entrevistados citaram que se incomodavam quando o intérprete não entendia o que estavam querendo dizer.

\section{Considerações finais}

$\mathrm{Na}$ modalidade da interpretação de acompanhamento é muito importante que se observe elementos da conduta profissional, como vestimenta adequada, pontualidade, cordialidade. Essas são exigências dos clientes. Por meio das análises de alguns exemplos da literatura pertinente, constatou-se que grande parte dos problemas ocasionados na interpretação 
TORRES, M. L.; SILVA, J . - Comportamentos e atitudes essenciais na interpretação de acompanhamento:

A perspectiva dos clientes

surge não apenas por falta de conhecimento linguístico, mas também da pouca familiaridade cultural.

Diante dos resultados obtidos a partir das entrevistas com profissionais da área de cerâmica que já utilizaram os serviços de intérpretes de acompanhamento, observa-se que, para uma interpretação bem sucedida, faz-se necessário o conhecimento técnico por parte do intérprete e, tão importante quanto isso, que ele esteja familiarizado com os equipamentos a serem utilizados.

$\mathrm{Na}$ análise do conteúdo das respostas, constatou-se que os intérpretes devem demonstrar que estão trabalhando de maneira confiável e honesta para com o cliente a fim de criar um laço de confiança com este. Além disso, outra questão levantada foi de que o intérprete deve estar atento quanto à interpretação por ele realizada para evitar um discurso reduzido do que foi falado. Esse demonstrou ser um elemento essencial para sua face validity. A face validity do intérprete pode aumentar se este tomar a precaução de deixar claro que (i) transmitiu todas as informações relevantes ao produzir um discurso comensurável em tempo com o da pessoa que está interpretando; (ii) se preparou previamente para a interpretação; (iii) está interessado na tarefa que realiza; (iv) está disposto, descansado e feliz.

\section{Referências bibliográficas}

AnASTASI, A. Psychological testing. New York: MacMillan, 1988.

BLAAUW, J. W. H.; RANKIN, I. Interpreting basics: study guide for TRNL 312. Potchefstroom: Potchefstroom University for Christian Higher Education, 200? Disponível em: $\triangleleft t t p: / /$ www. google. com. br/ url?sa $=t \& r c t=j \& q=\&$ esrc $=s \&$ source $=w e b \& c d=1 \& s q$ $\mathrm{i}=2 \&$ ved =0CCoQFj AA\&url =http\%3A\%2F\%2Fework- 
TORRES, M. L.; SILVA, J . - Comportamentos e atitudes essenciais na interpretação de acompanhamento:

A perspectiva dos clientes

win. puk. ac.za\%2Fsgo\%2Fdocs\%2Fskrywerfinaal\%2FTRNL $\% 2520312 \% 2520 \mathrm{E}-$

SGB02652. doc\&ei =tTOeUcG] D4es4AOB9IGwBQ\&usg=AFQj CNGuYsZCdj PNa5j gvE TpmTcpaB7HPw\&bvm=bv. 46865395, d.dmg>. Acesso em: 05 mar. 2013.

GAZETA, S. M. Outras modalidades de interpretação. In: SCHÄFfER, A. M.; TORRES, M. L. (Orgs.). Interpretação: a arte da interpretação simultânea, intermitente e consecutiva. Engenheiro Coelho: Edição do Autor, 2012. p. 163-178.

Gentile, A.; Ozolins, U.; Vasilakakos, M. Liaison interpreting: a handbook. Melbourne: Melbourne University Press, 1996.

HERBERT, J. The interpreter's handbook: how to become a conference interpreter. Genebra: Librairie de I'Université, 1952.

HSIEH, E. The importance of liaison interpreting in the theoretical development of translation studies. Urbana: University of Illinois, 2003.

Ingram, E. Basic concepts in testing. In: Allen, J. P. B.; Davies, A. (Eds.). Testing and experimental methods. London: Oxford University Press, 1977.

Kelly, N.; ZETZSCHE, J. Found in translation. Nova lorque: Penguin, 2012.

LA SALA, M. C. Liaison interpreting as a teaching technique for Italian. Southampton: University of Southampton, 2008. Disponível em: <www. llas.ac.uk/ resources/ paper/ 3231>. Acesso em: 12 jun. 2013.

MILTON, J.; VILLA, D. Os escritos clássicos ingleses sobre a tradução - 16151791. São Paulo: Humanistas, 2012.

Moraes, R. Análise de conteúdo. Revista Educação, Porto Alegre, v. 22, n. 37, p. 7-32, 1999. Disponível em: «ttp:// cliente.argo.com. br/ -mgos/analise_de_conteudo_moraes. html>. Acesso em: 26 out. 2013.

OBST, H. White House interpreter. Bloomington: Authorhouse, 2010.

SARTORI, R. Face validity in personality tests: psychometric instruments and projective techniques in comparison. Quality and Quantity, Amsterdam, v. 44, n. 4, p. 749-759, 2010.

SCHÄFfER, A. M. de M. Historiografia da interpretação. In: SCHÄFfER, A. M.; TORRES, M. L. (Orgs.). Interpretação: a arte da interpretação simultânea, 
TORRES, M. L. ; SILVA, J . - Comportamentos e atitudes essenciais na interpretação de acompanhamento:

A perspectiva dos clientes

intermitente e consecutiva. Engenheiro Coelho: Edição do Autor, 2012. p. 2547.

TORRES, M. L. Introdução. In: SCHÄFFER, A. M.; TORRES, M. L. (Orgs.). Interpretação: a arte da interpretação simultânea, intermitente e consecutiva. Engenheiro Coelho: Edição do Autor, 2012. p. 9-23. 